\title{
Measuring Performance - Conceptual Framework Questions ${ }^{\#}$
}

\author{
Jaroslav WAGNER ${ }^{*}$
}

\section{Introduction}

Measuring performance seems to be the never-ending story of managers, consultants and academics. Many books, reports and papers deal with questions like "Which dimensions of performance should be measured? What is the role of performance measurement in corporate performance management? How can we find the balanced mix of performance measures? Shall we concentrate on shareholders' or stakeholders' point of view? How report and communicate performance information to users?”

Reading different areas of "performance literature" like performance management systems, management control and accounting systems, external and internal reporting etc., all of them are dealing with performance measurement issues. However it seems that they concern "different worlds" and they cannot correspond together. Following this notion the question arises if there are some features which are consistent for all performance-relating topics. Because of different background, authors - respecting style which is favorite or ordinary in particular subject fields - contextualize performance issues in different ways. Moreover in some fields (like environmental management etc.) a little averse to expressions "performance" or "performance measurement" is evident because they are considered as profaned.

\footnotetext{
This paper was prepared in the framework of research plan Development of Accounting and Financial Theory and its Application in Practice from Interdisciplinary Point of View (registered number MSM 6138439903) and The Role of Methods and Tools of Managerial Accounting for Corporate Governance registered by the Grant Agency of the Czech Republic under the registration number GA402/07/0153.

* Ing. Jaroslav Wagner, PhD. - senior lecturer; Department of Managerial Accounting, Faculty of Finance and Accounting, University of Economics Prague, Winston Churchill sq. 4, 130 67, Czech Republic, <wagner@vse.cz>.
} 
This paper aims to formulate some principal questions which should be used as start-point for the conceptual framework. The performance measurement framework is proposed for application in both situations, while designing as well as analyzing systems or approaches to measure performance information. The paper is based on literature study followed by analysis and generalization.

The paper is divided into two sections. First section brings some general comments to measurement for performance information as a set of specific activities. Second section shows the role of performance model design for performance measurement process. The role of performance measurement for performance management process is emphasized in this section.

\section{Measurement for performance information}

In correspondence with performance the term "measurement" is used to characterize the status and progression in performance dimension of organizational existence. Despite of wide-spread application in professional literature as well as in everyday use there are some methodological objections regarding its usage in conjunction with performance.

Wikipedia (2008) defines measurement as the estimation of the magnitude of some attribute of an object. In applied social sciences measurement is often based on scaling and comparative statements concerning the characteristics of an attribute. However, performance expresses complex quality of organizational existence rather than particular attribute which could be defined exhaustively. Insuperable impact of subjectivity by measurement process and inseparability from evaluating procedures belong to implicit characteristics of performance measurement. With some exaggeration Meyer (2005) states that "the performance of the firm is fundamentally different from other kinds of performance ... because it is neither observable nor measurable”.

As noted below these matters are manifested in all activities relating to performance measurement process. In addition to pure compendium of individual performance measures, statements, judgments and intuitive perceptions form performance reporting. For these reasons, it seems to be more suitable to handle with such words as performance mapping or rather performance assessment (see Marr, 2006) in this context. 
"Performance mapping” emphasizes relevance of design of performance model for appropriate performance measurement. "Performance assessment" underlines interpretative context of performance information.

As the measurement belongs to expressions of our everyday language, notions of its scope differ significantly. The measurement as both, activity of identifying and assigning of the magnitude of some defined attribute as well as the result of this activity is the most frequent understanding. However, focusing performance measurement issues in the literature (performance) measurement is perceived as a set of align activities where identification or assignment of the magnitude is recognized as important but not exclusive element. ${ }^{1}$

For instance Marr (2004) distinguishes following activities in performance measurement process: (1) build a business (performance) model, (2) collect data, (3) analyze and interpret data, (4) extract and communicate insights. Such definition of performance measurement area exceeds above mentioned approach evidently. It shows performance measurement process as structured, output-oriented process.

Performance model design and development will be analyzed in the following part closely. There is no doubt that the way how performance model is designed influences following phases significantly. However it would be misunderstanding to hold these phases as deterministic and free of impact of subjectivity. Next articles bring some illustration of these ideas.

Proper classification and structuring of gathered data needs correct definitions for components of performance model. These definitions should be understandable to and accepted by all involved employees. Marr (2004) gives an example of company where 18 different definitions of the term "on time delivery" were formulated by different managers, despite of the fact that this measure was included in corporate performance model. Experts and advisors focusing on sophisticated performance model design and reports sheets refinements, but "ordinary" administration staff dealing millions of records without adequate

1 This approach refers to widespread notion typical for performance measurement literature. On the other hand, some authors respect roots of the term "measurement". For instance, Riahi-Belkaoui (2004) dealing with the nature of measurement in accounting suggests that "it is generally considered that accounting is a measurement as well as a communication discipline. 
specification (because further specification does not exist or employees are not able or do not want to interpret it), that is typical picture from many companies.

Although data structuring and analysis are based on performance model and they make towards communication of performance information, some principles are necessary for their processing. For example The Framework for the Preparation and Presentation of Financial Statement published by IASB sets four principal qualitative characteristics as the attributes that make information provided in financial statements useful to users (understandability, relevance, reliability and comparability) followed by constraints on information (such as timeliness or balance between benefit and costs). Evidently the way how these principles are taken into account depends on competency but also intention of people involved it their application.

Moreover, there are different opinions regarding the questions "how data interpretation should correspond to performance model designed in advanced" and "if the subjectivity should be eliminated during the interpretation phase". Consider, for instance, performance information for managers' evaluation and rewarding. Ittner, Larcker and Meyer (2003) show- despite of built-up performance model - subjectivity in weighting the measures involved in a balanced scorecard which was initiated by supervisors and which resulted to modified explanation of branch managers' performance and consequently to impact on managers' evaluation and rewarding. They conclude that the subjectivity "led many branch managers to complain about favoritism ... and uncertainty in the criteria used ...”.

From the different point of view Manzoni (2002) means that High Performance firms "....are no longer trying to minimize the presence of managerial judgment in subordinate performance evaluation ..." as "we will only know at the end of the year how well we did vs. competition given circumstances, hence we reserve the right to assess managerial performance at the end of the year taking into account all parameters in a process that is bound to involve some managerial judgment/subjectivity". Kaplan and Norton (2006) emphasize the relevance of strategic framework followed by adequate communication for interpretation and reporting of performance information; “...communication by leaders is critical. Employees cannot follow if executives do not lead...”. 
It is not the objective of this paper to deal with rewarding systems. We mentioned these ideas just to show different opinions concerning the role of subjectivity by interpreting gathered performance data.

To summarize this section, it seems to be appropriate to understand (performance) measurement as a chain of activities. Starting by performance model design all activities of performance measurement process (gathering, analyzing, interpreting and communicating performance information) are influenced by people who deals with "measurement" and their subjective notions. The impact of (negative manifested) subjectivity depends on consistency in "task specification" for individual activities, on competency and intention of people involved in measurement process and last but not least on quality of communication among users and providers of performance information. Due to subjectivity as well as evaluating features in performance information the term "measurement" is rather misleading in context of organizational performance information. Performance mapping or performance assessment seems to be more adequate expression for mentioned area of activities.

\section{Performance model}

As promised above following section will be aimed at performance model. Term "model" (intentionally in singular) underlines a comprehensive concept of performance measurement as well as the diversity of relations among particular components. Forming an "integrated whole", i.e. developing a system for performance measurement is more mission or optimum status rather than natural characteristic of performance model.

Despite of diversity of performance sub-models in organizations we assume there are some characteristic features which can be recognized in any performance model. A set of questions will be proposed which allows developing a framework for design and analysis of performance model. These conceptual questions should serve as a basis for designers and redesigners of performance model as well as for users and other professionals who deal with performance model analysis. As Enderle and Tavis (1998) accentuate “...if the concepts implied in measurement are unclear, measurement is unclear as well”. 
These questions overlap substantially so their distinction is intended as methodical tool for further analysis. They can be formulated as follows:

- What is (or was) the primary motivation for performance model design or for initiatives to redesign it?

- Who belong to its main users and for what purposes is the model designated? Are (or were) requirements and rules for the model design specified in advance? Who do (did) it?

- Is the model intended to cover investigated reality as a whole (holistic models) or rather some specified elements and dimensions of reality (pragmatic models)?

- Does the model emphasize synthetic (general) or analytic performance information (synthetic or analytic model)? If both, what types of analytical information are used and how the relations at sub-hierarchical levels are set?

- How is the time dimension specified in the model?

- Is the relevance of the model subject of assessment and validation? Is the feedback from users taken into account? Is the model adaptable?

- Are (or were) rules and procedures for following phases of performance measurement process (such as the way of classifying, structuring and reporting of performance information) specified in the linkage to model design?

\section{Motivation for performance model}

Composing performance model variety of motivational aspects plays its role. Designing or developing performance model, if we understand them it will help us to differentiate such aspects that affect core components of model from marginal or ad hoc incentives which can be misleading for our primary focus. Analyzing performance model it will help us to recognize initial reasons which shaped the state-of-the-art.

At the general level, extrinsic and intrinsic motivation aspects can be distinguished. In some cases motivation pattern can be recognized distinctly (such as performance measurement model for tax purposes because such models are design obligatory). However, primary motivational aspects are often mutually coherent. For example, consider performance models using environmental management accounting 
approach. On the one hand, application of environmental management accounting is strongly supported by governments as well as local and international public organizations (extrinsic incentives). On the other hand, "the general use of EMA information is for internal organizational calculations and decision-making", and thus it should follow intrinsic aims (see e.g. Environmental Management Accounting Procedures and Principles - United Nations, 2001).

Studying motivational reasons for performance model first, design of original performance model, and second, redesign or extension of the model based on users' additional information needs or performance measurement initiatives should be distinguished.

Davila and Foster (2007) examined adaption of management control systems in early- stage startup companies. They found that the transition from an informal approach to formal systems is induced by company size (manifested by number of employees in the study), venture capital financing (bringing experience into the company through the hiring of key managers), managers' experience and founder replacement by the professional CEO. Let's suppose that new CEO or manager does not introduce new formal system to become famous or "hero" (even if it is not excluded) and that internal reasons for adoption exists nevertheless external incentive for adoption of formal system (including performance model) was necessary.

Bourne et al. (2002) studied reasons for the success and failure of performance measurement initiatives in organizations with developed performance measurement models. They recognized top management commitment and the benefits from performance measurement as the two main factors which drove implementation. However, they identified that many of managers were able to reflect on the perceived benefits of the performance measurement initiatives after they were implemented.

There are a lot of knowledge about the benefits and pitfalls of application of performance measurement initiatives while a few findings on motivation for them. Extracting findings and own experience we suppose that some of key (extrinsic and intrinsic) motivational incentives are new requirement imposed by legal regulation, joining the harmonization process within corporation or economic community, changes in owners' and top management structure, changes in internal 
environment and organizational structure, new organizational strategy etc. $^{2}$

\section{Users and purposes of performance information}

Who are the users of performance information and why they need it? There is a large variety of ways how to answer both of these questions. Using, for instance, deductive approach for first of them external and internal users (parties) can be distinguished. ${ }^{3}$ Such approach is used in accounting literature usually (see e.g. Drury 2004; Atkinson et al., 2004). It emphasizes restricted access of external users to performance information (in relation to internal users) which causes the information asymmetry. As a result, application of qualitative characteristics of performance information, namely level of aggregation, ways for verification or understandable communication format etc. differs according to users' requirements.

From the slightly different point of view, stakeholders and business "managing agents" can be distinguished. Atkinson et al. (1997) perceive the organization as "...a complex web of contracts ... that specifies relations between company and its stakeholders. A stakeholder is an individual or group, inside or outside the company, that has a stake in or can influence the organization's performance”. Using this approach the role of managers is twofold. First, they are specific group of stakeholders, and second, they are agents hired by principals (i.e. stakeholders) to achieve and integrate their interests.

2 Sometimes new performance measurement initiative can be driven by individuals at subordinate or subdivision level in the company (for instance divisional manager or controller). Either top management commitment is achieved immediately or the initiative becomes unpracticed and profitless usually (see Kaplan and Norton 1996). Performance initiative managed as a project is the typical aftermath of such approach.

3 Note that differentiation of external and internal users of performance information refers to other issue than extrinsic and intrinsic motivational aspects for performance model design which were mentioned above. The first helps us to recognize the incentives for performance model design. The second one helps us to consider how users' information needs are satisfied (according to their position to performance information flows). The situation that performance information for external users is initiated within company and vice versa occurs naturally. Consider, for instance, lowcost airlines company which starts to measure and communicate percentage of ontime flights to attract business customers to their service. 
Ideas of stakeholders' impact ${ }^{4}$ on performance measurement are varied, especially concerning the hierarchical structure of balance performance model. Despite of apparent incompatibility of these approaches all of them respect two leading facts:

- The interest of owners (shareholders) is particularly significant.

- The interests of other stakeholders are unexceptionable.

Atkinson et al. (1997) suggest a compromise approach. They differentiate primary objectives, which are defined by the organizations' owners, and secondary objectives, which "are important not in their own right, but because they are instrumental in helping the company achieve its primary objectives. The similar idea is inherent to Balanced Scorecard concept using cause-and-effect approach where financial perspective means the definite effect for shareholders.

Centering shareholder value as a crucial issue of performance reporting and saying that objectives of other stakeholders should be respect because they make a boundary of shareholder value increase ("shareholder value approach"), or talking about the network of stakeholders' objective which should be balanced ("balanced stakeholder value approach"), it seems to be more rhetorical position rather than difference concerning subject of matter.

Concerning managers' area there is a great variety of approaches how to discourse roles of performance information for managers. Let's sample some of them. Simons (1999) differentiates information for decision making, control, signaling, and education and learning. Marr (2006) concentrates on controlling people's behavior, strategic decision-making and organizational learning. Using a general point of view, Neely et al. (1995) conceive performance measurement as the process of quantifying the efficiency and effectiveness of the action.

4 Enderle and Tavis (1998) suggest ethical concept based on the idea that organization should respect three dimensions (realms) of corporate responsibilities in balanced concept - economic, social and environmental realm. They mean that “... by listening to, and negotiated with, the stakeholders, the question about the specific contents of corporate responsibilities is not answer yet. In contrast, the balanced concept view emphasizes the question of what the company ought to do in economic, social and environmental terms". 
Atkinson et al. (1997) suggest that performance measurement should help the company to understand and evaluate the value received from suppliers and employees, the value provided to the stakeholders, the efficiency of organization's processes and organization's strategic properties. For these issues performance measurement plays coordinating, monitoring and diagnostic role. Enderle and Tavis (1998) relate performance measurement to three steps in which organizational responsibilities should be translated into action - strategic positioning, resource commitments, and assessment.

To generalize this recital, following features of performance measurement models for performance management can be extracted. Many empirical researches prove these statements evidently (see e.g. Marr et al., 2006; Tapinos et al., 2005; Wagner et al., 2007).

- Linkage to strategic dimension of managerial issues (strategic positioning, strategic properties, strategic decision-making etc.).

- Combination of routine as well as on-demand performance information (monitoring versus signaling, diagnostic role).

- Alignment of people's behavior with organizational goals (control people's behavior, coordinating, resource commitment and assessment etc.).

- Focus on continual improvement (education and organizational learning).

\section{Definition of object of measurement}

As Enderle and Tavis (1998) suggest "measurement involves abstraction. It inherently concentrates on some aspects while disclaiming others”. Measuring real organization's performance is like seeking to transmit nature and its beauty. We try to bring someone to touch the reality. And the performance model should be a tool for that.

Illustrate the beauty of nature we can focus on pictures of landscape using 3D video system, on sounds and noise using surround audio systems, on smells, on taste even on touch by some means of simulation. Or we can try to put these components together to bring even more and to reach for complex power of such model. Analogically, to illustrate the performance we can focus on some selected characteristic of examined 
reality (pragmatic models) or we can search for comprehensive approach which maps the object as a whole (holistic models). ${ }^{5}$

The reasons for developing a holistic model can be twofold; either it corresponds to nature of user's requirements, or all potential users and their informational needs are not known in advance. In the second case designer of performance model bears the notion of model homogeneity and its adaptability to specific users' requirements while communicating performance information.

According to applied hierarchical level, holistic models can be constitute to cover (1) the entire organization as a socio-economic system (entity), (2) defined element of this entity ${ }^{6}$, (3) managers' and employees' behavior in correspondence with both, the organization as well as its elements. The first two issues relate to performance of object per se (so called organizational and intra-organizational performance), the third issue refers to (so called) managerial performance.

Regarding to need for horizontal coordination with suppliers, interorganizational performance models can be developed to integrate supply chain performance in the model (see e.g. Schmitz and Platts, 2003 or Beamon, 1999).

In addition to hierarchical level, designing pragmatic model some characteristic feature, on which the model focuses primarily, has to be specified. Feature specification concentrates on interactions of the object with (external as well as internal) environment usually, i.e. on the way how the object responds to some area of incentives from environment as well as how it affects its environment in corresponding area.

\section{Synthetic and analytic performance model}

"The primary objective of an income statement should be to enable users to differentiate between different types of gains and losses ... and hence, facilitate forecasting $\ldots$ of future performance. In addition ... through appropriate subtotals, provide relevant measures of historical

5 Note that comprehensiveness in holistic models refers to the variety of dimensions included in the model and not to the extension of searched object.

6 Some authors (see e.g. Svoboda, 2000) differentiate two main hierarchical sub-levels in organizational structure, namely subsystems and elements. 
performance. Investors should be able to make use ... [it] ... as a means of judging performance..." (Cooper 2007)

"Performance measurement systems should contain many nonfinancial indicators to complement financial ones, particularly with respect to customer perceptions and performance of internal processes." (Epstein and Manzoni, 1997)

"The literature has suggested that firms should put much more emphasis on nonfinancial measures in comparison to financial measures ... This study shows that ... financial measures are much more used by controller than non-financial measures.” (Gosselin, 2005)

"Tracking things like customer satisfaction and employee turnover can powerfully supplement traditional bookkeeping. Unfortunately, most companies botch the job.” (Ittner and Larcker, 2003)

"Organizations are often prepared to sacrifice rich realities in order to achieve alleged rigor and clarity through measures". (Marr, 2006) "...the most organizations tend to measure what is easy to measure and not necessarily what really matters.” (Marr, 2004)

"I am a firm believer in reduction in performance measurement. Rather than attempting to find aggregate measures, whether of customer satisfaction, employee satisfaction, productivity, and the like, predicting aggregate firm revenues and profits, I believe that it is better to focus on highly disaggregated measures” (Meyer, 2005).

We let ourselves bring in so many citations to show the great and variegated package of views in both, academic as well as managerial literature concerning the question how to measure performance. ${ }^{7}$ They are full of belief, imperative as even disillusion statements. We consider to be neither competent to assess mentioned ideas nor responsible for it. Moreover, we consider as redundant to join this discussion with other

\footnotetext{
Similarly to extrinsic/intrinsic motivation versus external/internal differentiation we suggest that the scope of object measured (what to measure) and depth and breadth of measuring model (how to measure) should be distinguished. For example, decision to use financial measures in a performance model refers to particular characteristic of model not to characteristic of measured object. However, corporate financial reporting - even based on financial information solely - represents pragmatic model of organizational performance because of materiality concept.
} 
judgments. Therefore, despite of some shallowness we would rather give a general account of performance model structure:

(1) Aggregating different characteristics, financial summary measures are used at the top (synthetic) level usually. If the only basis of measurement is applied for specific object of measurement ${ }^{8}$, onedimensional model is designed as a result. If the more bases are applied, multi-dimensional model is designed.

(2) Getting ${ }^{9}$ on analytical level two principal approaches can be applied (or combined):

a) Disaggregation of financial measures to analytical financial measures using the same type of measures. Two conceptual ideas relate to such disaggregation. First of them suggests that "the whole equals to the sum of its parts”. If we consider this idea analytical financial measures are subtotals of aggregate financial measure. Du Pont Analysis for ROE or Variance Analysis in standard costing belongs to typical examples of this approach. Second idea implies that "the whole is more than the sum of its parts". Respecting this notion summary measure transcends the aggregation of analytical measures and additional measurement should be applied at higher hierarchical level (consider e.g. goodwill in accounting model). ${ }^{10}$

b) Design of causal relationship model which uses both, financial and nonfinancial performance measures at analytical levels. Concerning this approach following issues should be identified by the model: (1) which measures (or their group) relate to performance of object, (2) how relevant an individual measure (or a group of measures) is for performance, (3) do the measures link consequently (one individual measure is caused by second one) or mutually (measures in two-way relationship). Balanced Scorecard is the well known example of this approach.

8 Although different basis of measurement are applied for different objects.

9 Many illustrative terms are used in literature to describe objective of this phase, e.g. transforming, cascading, translating etc.

10 Of course, inverse situation can occur, i.e. "the whole can be less than the parts”. 


\section{Time dimension in performance model}

Performance manifests the evolution of existence of an organization. Thus, it relates to progression in time inherently. Concerning performance model time dimension should be considered in following areas.

(1) Definition of performance model objective

Different time dimension in performance model objective could be illustrated by following pair of questions:

"Which performance-relevant matters happened and manifested as required in a specific time period?”

"What way of development can be expected based on matters which happened, which happens, perhaps even which may happen?”

First of these questions refers to performance model as the tool for registering and explain the course of matters (explanatory approach). Second one emphasizes predictive role of performance measurement model (predictive approach). Corresponding to that, Kaplan and Norton (1996) distinguish leading (predicting) and lagging (explaining) performance indicators to emphasize that both approaches can be covered by one performance model.

(2) Choice of types of performance measures

Riahi-Belkaoui (2004) distinguishes retrospective, contemporary and prospective (accounting) measures "to refer to whether the accounting object or its attribute measures belong to a past, present or future event relative to the time at which measurement is made". It is evident that retrospective and contemporary measures can be applied in compliance to explanatory approach which was mentioned above.

On the other hand, all three types of measures can be applied keeping predictive approach. For instance, Cooper (2007) suggests discussing historical costs and fair value as bases for calculating depreciations - that "although historical cost and related depreciation charges can easily be criticized, in many cases, such a measurement basis produces perfectly acceptable measure of performance”. 
(3) Setting time period (or standard length of period) relevant for performance measurement.

Continuity of existence (and performance) and discontinuity in measuring and communicating performance information, that is everlasting problem for performance measurement model. "From the beginning to the present" or "from now until the end" even "for the entire existence", such specifications are unacceptable for performance measurement generally.

Setting time period enables to evaluate the progression in performance during time or to compare the progression of different object, although it brings allocation and estimation problems.

\section{Cohesion, validation and adaptability of performance measurement process}

Despite everyone's best intention, homogeneity in performance model structure and cohesion within performance measurement process should be validated properly. Because these issues exceed the scope of this paper, let's just point out some findings from empirical research studies. For instance, Ittner and Larcker (2003) found out that only 23\% from 157 manufacturing companies involved in their research built and verified causal performance model. Research results from the Centre for Business Performance at Cranfield School of Management, UK (see Marr et al., 2004) show that "the most organizations tent to measure what is easy to measure and not necessarily what really matter".

Closing this section it is appropriate to emphasize that even the best performance model is an instrument which can help us to get correct performance information. Thus it can't be glorified per se but only by its users and through the way how their informational needs are met.

\section{Conclusions}

The term "measurement" is used to characterize the status and progression in performance dimension of organizational existence. It expresses complex quality of organizational existence rather than particular attribute which could be defined exhaustively. 
In everyday language the measurement as both, activity of identifying and assigning of the magnitude of some defined attribute as well as the result of this activity is the most frequent understanding. However, in the performance-oriented literature (performance) measurement is perceived as a set of align activities (designing performance model followed by gathering, analyzing, interpreting and communicating performance information) where identification or assignment of the magnitude is recognized as important but not exclusive element.

Insuperable impact of subjectivity by measurement process and inseparability from evaluating procedures belong to implicit characteristics of performance measurement. For these reasons, it seems to be more suitable to handle with such words as performance mapping or rather performance assessment in this context.

Despite of diversity of performance models in organizations we assume there are some characteristic features which can be recognized in any performance model and which can be characterized by a set of conceptual question. Such concept should serve as a basis for designers and redesigners of performance model as well as for users and other professionals who deal with performance model analysis. We suggest that these questions refer to (1) motivation for performance model, (2) users and purposes of performance information, (3) definition of object of measurement, (4) hierarchical structure of performance model, (4) time dimension in performance model, (5) validation of performance model and cohesion within elements of performance measurement process, (6) adaptability of performance model.

Analyzing the motivational aspects helps to understand various incentives which influence (or influenced) performance model design. Extrinsic and intrinsic motivational incentives are mixed together usually and they can differ if original performance model in a start-up company is designed or if a developed model is the subject of change.

Concerning users of performance information either external/ internal users or stakeholders and "managing agents" can be distinguished. If second concept is applied, interaction among stakeholders' objectives is often discussed, especially the position of shareholders in relation to other groups. Despite of diversity of opinions all of them respect that the interest of owners (shareholders) is particularly significant nevertheless, the interests of other stakeholders are unexceptionable. 
Regarding the role of performance measurement models for performance management, following features can be extracted: (1) linkage to strategic management dimension, (2) combination of routine and on-demand performance information, (3) alignment of people's behavior with organizational goals, (4) focus on continual improvement.

According to hierarchical level, performance models can deal with the organization as an entity or with defined element of this entity. Either performance of specified object or results of managers' and employees' behavior which relates to this object can be measured. Each measurement involves abstraction, so it concentrates on some aspects of reality. Depending on whether voluntary reduction of characteristics of searched object is applied, holistic and pragmatic models can be distinguished.

There is the great and variegated package of views in both, academic as well as managerial literature concerning the question how to measure performance. Nevertheless all of them agree that application of financial measures at the general level is necessary for aggregation of different dimensions. Different approaches concern the question how to make transformation to analytical level. Either disaggregation to analytical financial measures using the same type of measures or design of causal relationship model which uses both, financial and nonfinancial measures or some combination of them represent the key ideas.

Time dimension touches the performance models in three areas. According to users' needs the model can be designed to register and explain the course of matters which has happened (explanatory approach) as well as to predict future perspective (predictive approach). To achieve these objectives retrospective, contemporary, and prospective measures can be applied. While first two types of them correspond to explanatory approach, all three types come into consideration following predictive approach.

To evaluate the progression in performance during time or to compare the progression of different object, determination of time period relevant for performance measurement is necessary, although it brings allocation and estimation problems.

Despite everyone's best intention, homogeneity in performance model structure and cohesion within performance measurement process should 
Wagner, J.: Measuring Performance - Conceptual Framework Questions.

be validated. Otherwise spectacular performance measurement process of negligible relevance could become a result of extensive effort.

\section{References}

[1] Atkinson, A. A. - Kaplan, R. S. - Young, S. M. (2004): Management Accounting. Englewood Cliffs, Prentice Hall, 2004.

[2] Atkinson, A. A. - Waterhouse, J. H. - Wells, R. B. (1997): A Stakeholder Approach to Strategic Performance Measurement. Sloan Management Review, 1997, vol. 38, no. 3, pp. 25-37.

[3] Beamon, B. M. (1999): Measuring supply chain performance. International Journal of Operations \& Production Management, vol.19, no. 3, pp. 275-292.

[4] Bourne, M. - Neely, A. - Platts, K. - Mills, J. (2002): The success and failure of performance measurement initiatives. Perceptions of participating managers. International Journal of Operations and Production Management, 2002, vol. 22, no. 11, pp. 1288-1310.

[5] Cooper, S. (2007): Performance Measurement for Equity Analysis and Valuation. Accounting in Europe, 2007, vol. 4, no. 1, pp. 1-49.

[6] Davila, A. - Foster, G. (2007): Management Control Systems in Early-Stage Startup Companies. The Accounting Review, 2007, vol. 82, no. 4, pp. 907-937.

[7] Drury, C. (2004): Management and Cost Accounting. Florence, Thomson Learning, 2004.

[8] Enderle, G. - Tavis, L. A. (1998): A Balanced Concept of the Firm and the Measurement of Its Long-term Planning and Performance. Journal of Business Ethics, 1998, vol. 17, no. 11, pp. 1129-1144.

[9] Epstein, M. - Manzoni, J. F. (1997): The balanced scorecard and tableau de bord: Translating strategy into action. Management Accounting, 1997, vol. 79, no. 2, pp. 28-36.

[10] Gosselin, M (2005): An empirical study of performance measurement in manufacturing firms. International Journal of Productivity and Performance Management, 2005, vol. 54, no. 5-6, pp. 419-437.

[11] Ittner, C. D. - Larcker, D. F. - Meyer, M. W. (2003): Subjectivity and the Weighting of Performance Measures: Evidence from a 
Balanced Scorecard. Accounting Review, 2003, vol. 78, no. 3, pp. 725-758.

[12] Ittner, C. D. - Larcker, D. F. (2003): Coming Up Short on Nonfinancial Performance Measurement. Harvard Business Review, 2003, vol. 81, no. 11, pp. 88-95.

[13] Kaplan, R. S. - Norton, D. P. (1996): The Balanced Scorecard: Translating Strategy into Action. Boston, Harvard Business School Press, 1996.

[14] Kaplan, R. S. - Norton, D. P. (2006): Alignment: Using the Balanced Scorecard to Create Corporate Synergies. Boston, Harvard Business School Press, 2006.

[15] Manzoni, J-F. (2002): Management Control: Toward a new High Performance Paradigm. In: Horváth, P. (ed.): Performance Controlling. Strategie, Leistung und Anreizsystem effektiv verbinden. Stuttgart, Schäffer-Poeschel Verlag, 2002, pp. 79-93.

[16] Marr, B. (2006): Strategic Performance Management. Leveraging and measuring your intangible value drivers. Oxford, Elsevier, 2006.

[17] Marr, B. et al. (2004): Business Performance Management: Current State of The Art. [on-line], Cranfield / Egham, Cranfield School of Management / Hyperion, c2004, [cited 20 ${ }^{\text {th }}$ July, 2008], $<$ https://dspace.lib.cranfield.ac.uk/bitstream/1826/1222/1/BPR.pdf>.

[18] Meyer, M. W. (2005): Can Performance Studies Create Actionable Knowledge if We Can't Measure the Performance of the Firm? Journal of Management Inquiry, 2005, vol. 14, no. 3, pp. 287-291.

[19] Neely, A. - Gregory, M. - Platts, K. (1995): Performance measurement system design. International Journal of Operations and Production Management, 1995, vol. 15, no. 4, pp. 80-116.

[20] Riahi-Belkaoui, A. (2004): Accounting Theory. Florence, Thomson Learning, 2004.

[21] Schmitz, J. - Platts, K.W. (2003): Roles of supplier performance measurement: indication from a study in the automotive industry. Management Decision, vol. 41, no. 8, pp. 711-721.

[22] Simons, R. (1999): Performance Measurement \& Control Systems for Implementing Strategy. Text \& Cases. Englewood Cliffs, Prentice Hall, 1999. 
Wagner, J.: Measuring Performance-Conceptual Framework Questions.

[23] Svoboda, S. (2000): Information System of Business Entities. (in Czech: Informační systém podnikatelských subjektů). Praha, University of Economics, Prague, 2000.

[24] Tapinos, E. - Dyson, R. G. - Meadows, M. (2005): The impact of performance measurement in strategic planning. International Journal of Productivity and Performance Management, 2005, vol. 54, no. 5-6, pp. 370-384.

[25] United Nations (2001): Environmental Management Accounting Procedures and Principles. Working Paper. [on-line], New York, United Nations Division for Sustainable Development c2001, [cited $20^{\text {th }}$ July, 2008], <http://www.un.org/esa/sustdev/publications/proced uresandprinciples.pdf $>$.

[26] Wagner, J. - Šoljaková, L. - Matyáš, O. (2007): Strategic Performance Measurement and Compensation Systems in the Czech Republic (Empirical Study). European Financial and Accounting Journal, 2007, vol. 2, no. 3-4, pp. 8-26.

[27] Wikipedia (2008): Measurement. [on-line], Boston, Free Software Foundation, c2008, [cited $25^{\text {th }}$ August, 2008], $<$ http://en.wikipedia.org/wiki/Measurement>. 


\title{
Measuring Performance - Conceptual Framework Questions
}

\author{
Jaroslav WAGNER
}

\begin{abstract}
This paper aims to formulate some principal questions which should be used as start-point for design and analysis of the performance measurement conceptual framework. The paper is based on literature study followed by analysis and generalization. It reflects the diversity of approaches to performance measurement in performance-oriented literature and it investigates their similarities and differences.

The paper is divided into two sections. First section defines performance measurement as a causal chain of activities and it deals with the role of subjectivity in this chain. Second section concerns common features of various performance models for organizational performance, namely motivational aspects of performance model design, users and purposes of performance information, hierarchical structure and time dimension of performance model etc.
\end{abstract}

Key words: Organizational Performance, Performance Measurement, Subjectivity in Measurement

JEL classification: M41. 